\title{
The Influence of Soil pH on the Uptake of Silver Nanoparticles in a Terrestrial System
}

Sara A Pappas', Naveen Kumar', Uday Turaga1, Seshadri Ramkumar ${ }^{2}$ and Ronald J Kendall ${ }^{1 *}$

${ }^{1}$ The Wildlife Toxicology Laboratory, The Institute of Environmental and Human Health, Texas Tech University, Lubbock, TX, USA

${ }^{2}$ Nonwovens and Advanced Materials Laboratory, The Institute of Environmental and Human Health, Texas Tech University, Lubbock, TX, USA

\begin{abstract}
The production and use of silver nanoparticles (Ag NPs) are increasing in the United States and across the globe. The Ag NPs may enter the terrestrial ecosystem with the application of sewage sludge as a fertilizer on agricultural farms. The present study investigated the influence of soil $\mathrm{pH}$ on the uptake of $\mathrm{Ag} \mathrm{NPs}$ by insects. Two insects $A$. domesticus and T. molitor were selected for the experiment. The insects were exposed to Ag NPs under different soil $\mathrm{pH}$ including: 5, 6, 7, 8 (control), and 9. The Ag NPs were characterized prior to the study with transmission electron microscopy, dynamic light scattering, and powder X-ray diffraction techniques. The concentration of silver in insects was measured with inductively coupled plasma-optical emission spectroscopy. Increased levels of silver in insects was observed in normal and alkaline soil as compared to acidic soil treatment groups. Additionally, there was no significant difference due to insect species in the silver uptake.
\end{abstract}

Keywords: Silver nanoparticles; Terrestrial system; Uptake; Soil pH

\section{Introduction}

As increasing amounts of silver nanoparticles (Ag NPs) are manufactured and used, the quantities of silver released into the environment will also increase [1-4]. The unique properties of Ag NPs include antimicrobial, antifungal, and partially antiviral factors. These properties are associated with the increasing production and this trend is expected to continue in the future [5-7]. As of 2007, the United States annually released over $13 \mathrm{Gg}$ (14330 metric ton) of total (bulk and nano) silver into the environment, more than any other nation in the world [8,9]. According to Hendren et al. [10], the total production of Ag NPs in the United States was 2.8-20 metric ton/year and is growing. It is estimated that by 2025 the global Ag NPs market would be 800 metric ton [11]. There are many ways that Ag NPs can enter the environment, both intentionally and accidentally [12]. A potential route of entry of Ag NPs in the environment is waste water streams and effluent because the Ag NPs are retained in sewage sludge [13,14]. The sewage sludge is often used as a fertilizer in agriculture where it can move to the aquatic ecosystem through surface runoff or it can remain in the terrestrial environment $[13,15]$. Once Ag NPs are present in a system, their fate is uncertain since it is dependent on many interacting factors. The bioaccumulation and toxicity of heavy metals to soil inhabitants is a complex process which is determined by the soil characteristics, chemical form of metals, and physiology of organisms [16]. One of the driving factors in the terrestrial system could be the soil $\mathrm{pH}$. As with other metals, soil $\mathrm{pH}$ plays a significant role in the availability of silver nanoparticles Janssen et al. $[17,18]$. Soils with lower $\mathrm{pH}$ have an increased amount of $\mathrm{H}^{+}$which compete with silver ions for binding sites causing a larger amount of silver ions to remain free in the soil [18].

The bioaccumulation and toxicity of Ag NPs has been reported for soil organisms such as Eisenia fetida [19], Enchytraeus albidus [20], Porcellio scaber [21], and Folsomia candida [22], however, the data is limited for the uptake of Ag NPs by insects. Nanoparticles can transfer from one trophic level to the next along the food chain. According to Unrine et al. [23] gold nanoparticles can transfer from soil to terrestrial organisms. The transfer of heavy metals such as cadmium, lead, etc. across the food web has been recognized previously [14,2426]. Zhuang et al. [27] reported the transfer of lead from insect larvae to chickens (Gallus gallus domesticus). In the present study, two insect species (Acheta domesticus and Tenebrio molitor) were used as model organisms because these insects are soil dwelling and easy to culture [28-30]. Additionally, these insect species are native to the study area. Hence, the examination of the uptake of Ag NPs by these species would help us to understand the transfer of heavy metals along the food web in the native avian insectivore species such as Northern Bobwhite quail (Colinus virginianus). In this study, we investigated the influence of soil $\mathrm{pH}$ on the uptake of Ag NPs by insects.

\section{Materials and Methods}

\section{Soil collection and preparation}

All soil used during the insect exposure experiments was collected from the top $10 \mathrm{~cm}$ of soil from Colorado City (exact coordinates: 14 S $0319752 \mathrm{mE} 3557792 \mathrm{mN}$ ), Texas and transferred to The Institute of Environmental and Human Health (TIEHH) at Texas Tech University (TTU) in Lubbock, TX. Before use, soil was processed for homogeneity and sieved through a $2-\mathrm{mm}$ wire screen into a clean plastic storage container.

\section{Soil analysis}

Soil samples were analyzed at Midwest Laboratories Inc. (Omaha, NE, USA) for texture, percent humic matter, percent organic matter, exchangeable cations $\left(\mathrm{K}^{+}, \mathrm{Mg}^{2+}, \mathrm{Ca}^{2+}\right)$, available phosphorus $(\mathrm{P}), \mathrm{pH}$, percent base saturation of cations $\left(\mathrm{K}^{+}, \mathrm{Mg}^{2+}, \mathrm{Ca}^{2+}, \mathrm{H}^{+}\right)$, cation exchange capacity (CEC), and sulfur (S) content to characterize the soil.

\section{Nanoparticle characterization}

*Corresponding author: Ronald J Kendall, The Wildlife Toxicology Laboratory, The Institute of Environmental and Human Health, Texas Tech University, Lubbock, TX, USA, Tel: 8068850238; E-mail: ron.kendall@ttu.edu

Received January 24, 2018; Accepted January 27, 2018; Published January 30 2018

Citation: Pappas SA, Kumar N, Turaga U, Ramkumar S, Kendall RJ (2018) The Influence of Soil pH on the Uptake of Silver Nanoparticles in a Terrestrial System. J Environ Anal Toxicol 8: 545. doi: 10.4172/2161-0525.1000545

Copyright: @ 2018 Pappas SA, et al. This is an open-access article distributed under the terms of the Creative Commons Attribution License, which permits unrestricted use, distribution, and reproduction in any medium, provided the original author and source are credited. 
Citation: Pappas SA, Kumar N, Turaga U, Ramkumar S, Kendall RJ (2018) The Influence of Soil pH on the Uptake of Silver Nanoparticles in a Terrestrial System. J Environ Anal Toxicol 8: 545. doi: 10.4172/2161-0525.1000545

Page 2 of 5

All uncoated Ag NPs (30-50 nm) were purchased from US Research Nanomaterial, NC. (Houston, TX, USA). All Ag NPs were reported by US Research Nanomaterial, Inc. to consist of $\geq 99.99 \% \mathrm{Ag}$. The manufacturer also confirmed the size and spherical shape of each lot of nanoparticles. However, due to the tendency of nanoparticles to aggregate, the most significant properties, size and shape, were examined to confirm the manufacturer's specifications.

To confirm the size range and shape of the nanoparticles, transmission electron microscopy (TEM) was used. Each sample was prepared by dispersing the Ag NPs powder in ethanol (EtOH) and sonicated for 10 minutes before being drop cast onto a carbon coated copper grid. Samples were air dried before analysis. TEM (Hitachi $\mathrm{H}-8100$ TEM) images were taken at $200 \mathrm{kV}$ using a tungsten filament side-mounted camera.

Dynamic light scattering (DLS) was used as an additional method to confirm the nanoparticle size. Sample preparation was performed by placing approximately $10 \mathrm{mg}$ of silver nanoparticle powder in $10 \mathrm{~mL}$ of reagent grade acetone (Fisher Chemical, MA, USA) and analyzed using a Nanotrac NPA252 Combination (Microtrac Inc. Montgomery, PA, USA) and Mictrotrac Flex Software (Version: 10.3.14). Powder x-ray diffraction (PXRD) was used to confirm nanoparticle composition. A Rigaku Ultima III X-Ray Diffractometer was used to analyze all samples. Samples were analyzed using $\mathrm{Cu} \mathrm{Ka}$ radiation as $\mathrm{x}$-ray source. The Ag NPs were analyzed using the following instrument parameters: parallel-beam geometry was used with a step width of $0.03^{\circ}$ and a count time of one second; the divergence, scattering, and receiving slits were set at one. Once completed, the diffraction patterns were compared and matched to the phases in the International Center for Diffraction Data (ICDD) powder diffraction file (PDF) database.

\section{Insect treatment groups}

All insects were purchased from reptilefoods.com and randomly divided into treatment groups and control. The insects were transferred into a terrarium which had $2.5 \mathrm{~kg}$ of soil. Before each terrarium could be spiked with Ag NPs, the soil $\mathrm{pH}$ had to be adjusted. During the soil characterization, the control soil was found to have a $\mathrm{pH}$ of 8.01. Nitric acid $\left(\mathrm{HNO}_{3}\right)$ was used to reduce the soil $\mathrm{pH}$ from 8 to 5, 6, and 7 required for the treatment groups. It should be noted here that $\mathrm{HNO}_{3}$ was chosen over sulfuric $\left(\mathrm{H}_{2} \mathrm{SO}_{4}\right)$ and hydrochloric $(\mathrm{HCl})$ acids because silver nitrate $\left(\mathrm{AgNO}_{3}\right)$ is soluble, unlike silver chloride $(\mathrm{AgCl})$ and silver sulfide $\left(\mathrm{Ag}_{2} \mathrm{~S}\right)$. By using $\mathrm{HNO}_{3}$ in place of $\mathrm{H}_{2} \mathrm{SO}_{4}$ or $\mathrm{HCl}$, it was ensured that the Ag NPs would remain in solution rather than precipitating out. To adjust the $\mathrm{pH}$ of each treatment group, small volumes of $\mathrm{HNO}_{3}$ were added to each experimental tank and dried overnight. The following day the soil was thoroughly mixed and allowed to sit for an additional day. A composite sample was then taken from each experimental tank and the $\mathrm{pH}$ was tested at 1: 1 soil: solution ratio with an Orion Star A211 pH Benchtop Meter (ThermoScientific).

As for the treatment group where the soil $\mathrm{pH}$ was equal to 9, commercially available garden lime (Espoma Organic Traditions Garden Lime) was used to increase the soil $\mathrm{pH}$. The garden lime was mixed with equal amounts of distilled water and small volumes were added to each terrarium as described above. The treatment and control groups soil $\mathrm{pH}$ are summarized in Table 1.

All terrariums were spiked with $25 \mu \mathrm{g} / \mathrm{g} \mathrm{Ag}$ NPs and thoroughly mixed to ensure homogeneity. Each terrarium received either $300 \mathrm{~A}$. domesticus or $400 \mathrm{~T}$. molitor. Insects were provided with fresh food (Fluker's Cricket Quencher ${ }^{\otimes}$ ) ad libitum for the 28 day exposure period. Once the exposure was complete, all insects were euthanized at $-80^{\circ} \mathrm{C}$.
The insects were then freeze dried (FreeZone 2.5 Liter Freeze Dry System, Labconco, Corp. Kansas City, MO, USA) for at least 48 hours to ensure the removal of all moisture. Freeze dried insects were then crushed into a fine powder and stored in a freezer until they could be digested.

\section{Sample digestions}

Six samples were randomly collected from each terrarium, these weighed approximately one gram each and were placed into separate $100 \mathrm{~mL}$ beakers. It should be noted here that the weights are dry weight (dw) for the insects. The A. domesticus samples were calculated to be approximately $81 \%$ water; so, $1.00 \mathrm{~g}$ dry weight would correspond to roughly $5.25 \mathrm{~g}$ wet weight $(\mathrm{ww})$ whereas, the $T$. molitor samples were found to be approximately $39 \%$ water; so, $1.00 \mathrm{~g} \mathrm{dw}$ would correspond to $1.65 \mathrm{~g}$ ww.

\section{Silver analysis}

All samples were analyzed using a Teledyne Instruments (Hudson, New Hampshire) Prodigy High Dispersion Inductively Coupled Plasma Optical Emission Spectrometer (ICP-OES). All samples were analyzed for silver at three wavelengths: 224.643, 328.068, and $338.289 \mathrm{~nm}$. Ultimately, the data from $338.289 \mathrm{~nm}$ was chosen for statistical analysis. To ensure quality control throughout the run, the blank, 0.01 , and $10 \mathrm{ppm}$ standards were run at least once in each rack of 44 samples. Additionally, automatic check standard samples were run at various intervals throughout each run. The $0.05,0.5$, and $5.0 \mathrm{ppm}$ standards were analyzed every 10 samples. And the 0.1 and $1.0 \mathrm{ppm}$ standards were run every 20 samples. The standard samples were monitored throughout each run to ensure the instrument was constant in its analysis. Duplicate samples were also run at least once per batch to ensure consistency between runs.

\section{Statistical analysis}

The normality and distribution of variance of the data was examined before performing ANOVA. A two-way ANOVA was performed to compare the uptake of Ag from Ag NPs in soil at level $\alpha=0.05$. Two factors were considered for the analysis including: soil $\mathrm{pH}$ and insect species. Soil $\mathrm{pH}$ had five levels including: 5, 6, 7, 8, and 9, whereas insect species were $A$. domesticus and T. molitor. An interaction between the soil $\mathrm{pH}$ and insect species was also added to the model. This was followed by a Tukey's pairwise comparison test. The soil $\mathrm{pH}$ and insect species were treated as fixed type factors in the model. All statistical analysis was performed using Minitab 17. The concentrations below $0.02 \mathrm{ppm}$ were noted as zero during the data analysis.

\section{Results}

\section{Soil characterization}

The control soil was found to contain $54 \%$ sand, $36 \%$ silt, and $10 \%$ clay. This type of soil is classified as a sandy loam. The additional tests found the soil to contain $0.01 \%$ humic matter, $1.7 \%$ organic matter, and $9 \mathrm{ppm} \mathrm{S}$. The $\mathrm{pH}$ of the control soil was slightly basic, 8.1 and the CEC of the soil was calculated to be $18.0 \mathrm{meq} / 100 \mathrm{~g}$. Additionally, control soil samples analyzed by ICP-OES were found to contain no detectable concentrations of silver. The soil $\mathrm{pH}$ of treatment groups is summarized in the Table 1.

\section{Transmission electron microscopy}

The 30-50 nm uncoated silver nanoparticles were found to be heavily aggregated after being dispersed in EtOH. However, the TEM 
Citation: Pappas SA, Kumar N, Turaga U, Ramkumar S, Kendall RJ (2018) The Influence of Soil pH on the Uptake of Silver Nanoparticles in a Terrestrial System. J Environ Anal Toxicol 8: 545. doi: 10.4172/2161-0525.1000545

Page 3 of 5

could confirm the spherical shape of the nanoparticles (Figure 1). And most of the particles looked to be in 30-50 nm range, although there were outliers on either side of the range.

\section{Dynamic light scattering}

Approximately $95 \%$ of the $30-50 \mathrm{~nm}$ had a size between 30.70 to $52.90 \mathrm{~nm}$ (Figure 2). The average size of the particles was found to be $41.80 \mathrm{~nm}$, well within the parameters set by the manufacturers.

\section{Powder X-ray diffraction}

The PXRD analysis of the silver nanoparticles confirmed their composition. The diffraction patterns matched both those in the ICDD and those provided by the manufacturer. A typical diffraction pattern can be seen below (Figure 3).

\section{Silver analysis}

All method blanks and control samples were not found to contain detectable amounts of silver. All insect samples were found to contain a quantifiable amount of silver ( $>0.02 \mathrm{ppm}$, Limit of Quantitation) except A. domesticus from treatment group soil $\mathrm{pH}$ 5. A lower amount of Ag was observed under acidic conditions in both insects i.e., A. domesticus and T. molitor as compared to normal and alkaline soil environment (Figure 4).

\section{Data analysis}

The normality test shows that the data was normally distributed $(\mathrm{p}=0.738)$ and has a homogeneous distribution of variance. A twoway ANOVA was run on 60 samples of insects to examine the effect of the soil $\mathrm{pH}$ and insect species on the uptake of Ag from AgNPs in soil. There was a significant interaction between the effect of the soil $\mathrm{pH}$ and insect species on the uptake of $\mathrm{Ag}$ in insects, $\mathrm{F}(4,50)=29.87$, $\mathrm{p}=0.000$ (Figure 4). A simple main effect analysis showed that the effect of the soil $\mathrm{pH}$ on the uptake of $\mathrm{Ag}$ in insects was significantly different, $F(4,50)=72.84, p=0.000$, but there was no significant difference due to the insect species $(\mathrm{p}=0.602)$. Post hoc comparisons indicated that the mean uptake of $\mathrm{Ag}$ from treatment groups with normal to alkaline soil $(\mathrm{pH} 7,8$, and 9) was significantly higher than acidic soils (Figure 4).

\section{Discussion}

The transfer of heavy metals from soil to organisms is a complicated process. The soil physiochemical properties $(\mathrm{pH}$, cation exchange capacity, organic matter content, etc.), metal properties, nature of metal (essential vs non-essential), physiological state of organisms, and the route of exposure can affect the bioaccumulation/uptake of heavy metals [31]. It was expected that the samples from the treatment groups with lower soil $\mathrm{pH}$ values would contain more silver than those samples from the higher soil $\mathrm{pH}$ groups. The decreased $\mathrm{pH}$ of the lower treatment groups would have increased the amount of free silver ions present overall since metals dissolve in acidic environments. Additionally, soils with lower $\mathrm{pH}$ values have a decreased amount of $\mathrm{OH}^{-}$groups which provide additional binding sites for cations. However, the data from this study differ from this theoretical concept. The soil organisms may be exposed to nanoparticles by dermal or oral routes. Diez Ortiz et al. [32] reported that the ingestion of soil is a major route of exposure to Ag NPs in earthworms (Lumbricus rubellus) and the inhibition of soil ingestion result in the reduction of Ag NPs uptake. The data from the present study shows that the uptake of Ag NPs by A. domesticus and T. molitor was higher under normal and alkaline soil treatment groups as compared to the acidic soil. Bengtsson et al. [5] reported that the

\begin{tabular}{|c|c|}
\hline Soil Treatment Group & Measured soil pH \\
\hline 5 & $5.03 \pm 0.03$ \\
\hline 6 & $5.99 \pm 0.04$ \\
\hline 7 & $6.91 \pm 0.02$ \\
\hline 8 (Control soil) & $8.01 \pm 0.00$ \\
\hline 9 & $8.45 \pm 12$ \\
\hline
\end{tabular}

Table 1: Soil pH of insect treatment groups adjustment with $\mathrm{HNO}_{3}$ and lime

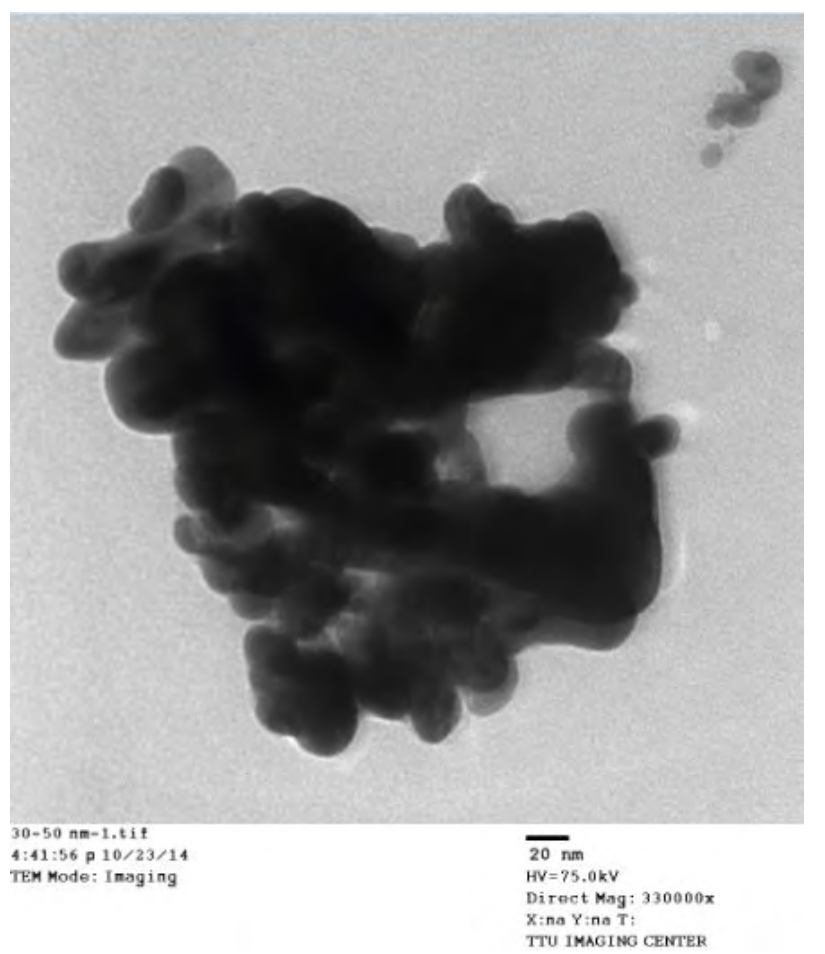

Figure 1: Transmission electron microscopy image for 30-50 nm uncoated silver nanoparticles.

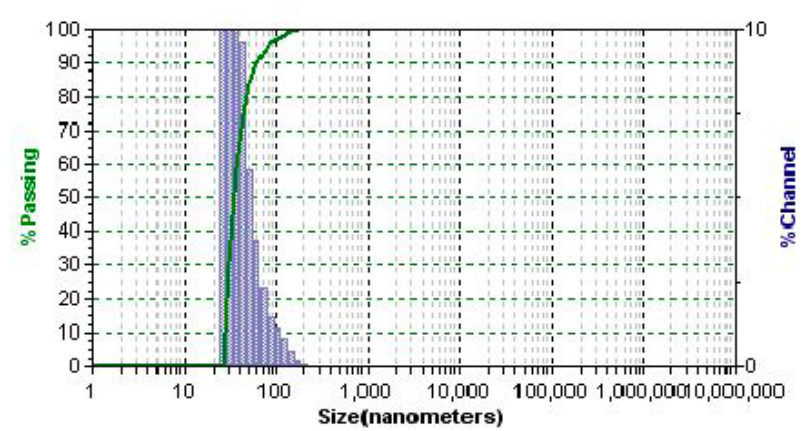

Figure 2: Size distribution of 30-50 nm uncoated silver nanoparticles determined by dynamic light scattering.

highest heavy metal concentration in tissues was not associated with the lowest soil pH in earthworms (Dendrobaena rubida). Based on data from the current experiment, we believe that the soil $\mathrm{pH}$ is playing an important role to facilitate the uptake of Ag NPs by both insects. It appears that acidic conditions reduce the feeding activity. Similarly, reduced earthworm growth and activity was also reported in acidic soils [33]. The feeding activity of soil fauna can be significantly boosted 
Citation: Pappas SA, Kumar N, Turaga U, Ramkumar S, Kendall RJ (2018) The Influence of Soil pH on the Uptake of Silver Nanoparticles in a Terrestrial System. J Environ Anal Toxicol 8: 545. doi: 10.4172/2161-0525.1000545

Page 4 of 5

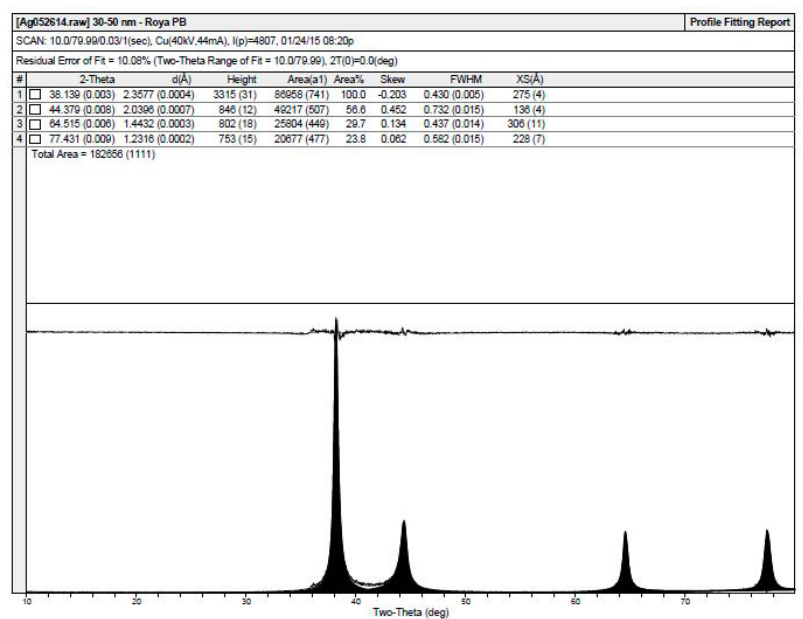

Figure 3: Diffraction pattern for 30-50 nm silver nanoparticles used in $\mathrm{pH}$ study as determined by powder x-ray diffraction.

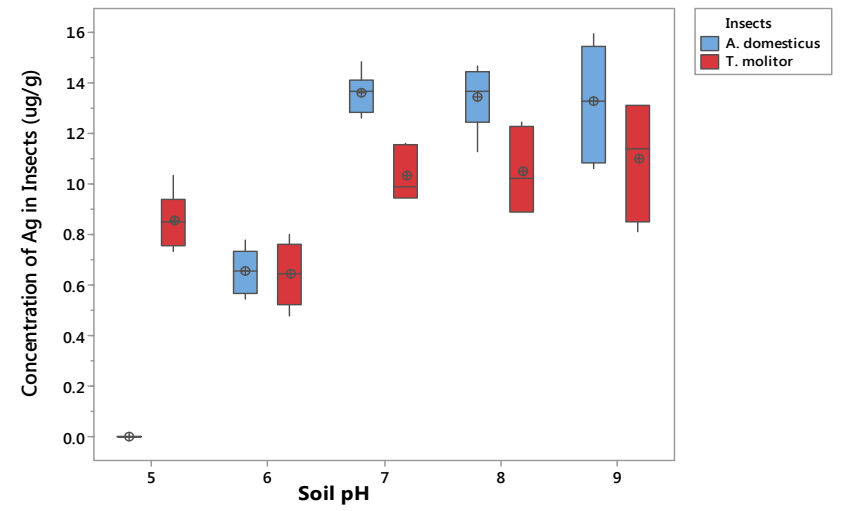

Figure 4: Influence of soil pH on uptake of Ag NPs by insects ( $A$. domesticus and T. molitor).

with liming the soil [34]. The feed consumption ratio in isopods (Porcellionides pruinosus) was higher at soil $\mathrm{pH} 7.3$ as compared to soil pH 6.2 and 4.5 [35].

The apparent decrease in feeding activity may have resulted in lower accumulation of Ag NPs in tissues. Furthermore, if the Ag NPs are simply adhering to the surface of the insects, the soil $\mathrm{pH}$ may not have had a large effect but we observed a difference in uptake due to soil $\mathrm{pH}$. Hence, we can confirm that the dermal exposure is not a major contributing route for exposure in these insects. It appears that feeding/ingestion activity is affecting the uptake of Ag NPs by insects. However, the mechanism by which these insects accumulate less Ag in acidic soil as compared to higher soil $\mathrm{pH}$ is not fully understood and will need a further study.

\section{Conclusion}

The present study shows that the soil $\mathrm{pH}$ influences the uptake of Ag NPs by A. domesticus and T. molitor. The high amount of Ag in the control group insects (soil $\mathrm{pH}$ 8.01) as compared to acidic soil indicates that the Ag may transfer to the next trophic level (native avian insectivore species). Further studies will be needed to clarify exactly how these silver nanoparticles are bioavailable to terrestrial insects and the role of soil $\mathrm{pH}$.

\section{Acknowledgements and Funding Details}

The authors would like to thank Sematech, TX for their financial contribution to this project. We also would like to thank Dr. Melanie A Barnes, Department of Geosciences, Texas Tech University, Ms. Roya Baghi, Department of Chemistry and Biochemistry, Texas Tech University, and Michael T Abel, Department of Environmental Toxicology, Texas Tech University, for all their valuable expertise, time and help with this project. Finally, we would like to extend our appreciation to the prospective Editors and Reviewers.

\section{References}

1. Klaine SJ, Alvarez PJ, Batley GE, Fernandes TF, Handy RD, et al. (2008) Nanomaterials in the environment: Behavior, fate, bioavailability, and effects. Environmental Toxicology and Chemistry 27: 1825-1851.

2. Lin D, Tian X, Wu F, Xing B (2010) Fate and transport of engineered nanomaterials in the environment. J Environ Qual 39: 1896-1908.

3. Lowry GV, Hotze EM, Bernhardt ES, Dionysiou DD, Pedersen JA, et al. (2010) Environmental occurrences, behavior, fate, and ecological effects of nanomaterials: An introduction to the special series. J Environ Qual 39: 18671874.

4. Kahru A, Dubourguier HC (2010) From ecotoxicology to nanoecotoxicology. Toxicology 269: 105-119.

5. Bengtsson G, Gunnarsson T, Rundgren S (1986) Effects of metal pollution on the earthworm Dendrobaena-rubida (Sav) in acidified soils. Water Air and Soil Pollution 28: 361-383.

6. Bone AJ, Colman BP, Gondikas AP, Newton KM, Harrold KH, et al. (2012) Biotic and abiotic interactions in aquatic microcosms determine fate and toxicity of Ag nanoparticles: Part 2 - Toxicity and Ag speciation. Environmental Science \& Technology 46: 6925-6933

7. Cleveland D, Long SE, Pennington PL, Cooper E, Fulton MH, et al. (2012) Pilot estuarine mesocosm study on the environmental fate of silver nanomaterials leached from consumer products. Science of the Total Environment 421: 267272.

8. Eckelman MJ, Graedel TE (2007) Silver emissions and their environmenta impacts: A multilevel assessment. Environmental Science \& Technology 41 6283-6289.

9. VandeVoort AR, Arai $Y$ (2012) Environmental chemistry of silver in soils: Current and historic perspective. Advances in Agronomy 114: 59-90.

10. Hendren CO, Mesnard X, Dröge J, Wiesner MR (2011) Estimating production data for five engineered nanomaterials as a basis for exposure assessment. Environmental Science \& Technology 45: 2562-2569.

11. Pulit-Prociak J, Banach M (2016) Silver nanoparticles-a material of the future...?. Open Chemistry 14: 76-91.

12. Miralles $P$, Church TL, Harris AT (2012) Toxicity, uptake, and translocation of engineered nanomaterials in vascular plants. Environmental Science \& Technology 46: 9224-9239.

13. Blaser SA, Scheringer M, MacLeod M, Hungerbühler K (2008) Estimation of cumulative aquatic exposure and risk due to silver: Contribution of nanofunctionalized plastics and textiles. Science of The Total Environment 390: 396-409.

14. Kaegi R, Voegelin A, Ort C, Sinnet B, Thalmann B, et al. (2013) Fate and transformation of silver nanoparticles in urban wastewater systems. Water Research 47: 3866-3877.

15. Jesmer AH, Velicogna JR, Schwertfeger DM, Scroggins RP, Princz JI (2017) The toxicity of silver to soil organisms exposed to silver nanoparticles and silver nitrate in biosolids-amended field soil. Environmental Toxicology and Chemistry 36: 2756-2765.

16. Babich H, Stotzky G (1980) Environmental factors that influence the toxicity of heavy metal and gaseous pollutants to microorganisms. Crit Rev Microbiol 8 99-145.

17. Janssen MP, Glastra P, Lembrechts JF (1997) The effects of soil chemica characteristics on the $134 \mathrm{Cs}$ concentrations in earthworms. Uptake from liquid medium. Journal of Environmental Radioactivity 35: 313-330. 
Citation: Pappas SA, Kumar N, Turaga U, Ramkumar S, Kendall RJ (2018) The Influence of Soil pH on the Uptake of Silver Nanoparticles in a Terrestrial System. J Environ Anal Toxicol 8: 545. doi: 10.4172/2161-0525.1000545

18. Bradl HB (2004) Adsorption of heavy metal ions on soils and soils constituents. $\mathrm{J}$ Colloid Interface Sci 277: 1-18.

19. Gomes SIL, Hansen D, Scott-Fordsmand JJ, Amorim MJ (2015) Effects of silver nanoparticles to soil invertebrates: Oxidative stress biomarkers in Eisenia fetida. Environ Pollut 199: 49-55.

20. Gomes SIL, Soares AMVM, Scott-Fordsmand JJ, Amorim MJB (2013) Mechanisms of response to silver nanoparticles on Enchytraeus albidus (Oligochaeta): Survival, reproduction and gene expression profile. Journal of Hazardous Materials 254-255: 336-344.

21. Tkalec ŽP, Drobne D, Vogel-Mikuš K, Pongrac P, Regvar M, et al. (2011) Micro-PIXE study of $\mathrm{Ag}$ in digestive glands of a nano-Ag fed arthropod (Porcellio scaber, Isopoda, Crustacea) Nuclear Instruments and Methods in Physics Research Section B: Beam Interactions with Materials and Atoms 269: 2286-2291.

22. Waalewijn-Kool PL, Klein K, Fornies RM, van Gestel CA (2014) Bioaccumulation and toxicity of silver nanoparticles and silver nitrate to the soil arthropod Folsomia candida. Ecotoxicology 23: 1629-1637.

23. Unrine JM, Shoults-Wilson WA, Zhurbich O, Bertsch PM, Tsyusko OV (2012) Trophic transfer of Au nanoparticles from soil along a simulated terrestrial food chain. Environmental Science \& Technology 46: 9753-9760.

24. Janssen MPM, Ma WC, Van Straalen NM (1993) Biomagnification of metals in terrestrial ecosystems. Science of the Total Environment 134: 511-524.

25. Gorree M, Tamis WLM, Traas TP, Elbers MA (1995) BIOMAG: a model for biomagnification in terrestrial food chains. The case of cadmium in the Kempen, The Netherlands. Science of the Total Environment 168: 215-223.

26. Mogren CL, Walton WE, Parker DR, Trumble JT (2013) Trophic transfer of arsenic from an aquatic insect to terrestrial insect predators PLOS ONE 8: e67817.
27. Zhuang $\mathrm{P}$, Zou H, Shu W (2009) Biotransfer of heavy metals along a soil-plantinsect-chicken food chain: Field study. Journal of Environmental Sciences 21 849-853.

28. Walton BT (1983) Use of the cricket embryo (Acheta domesticus) as an invertebrate teratology model. Fundamental and Applied Toxicology 3: 233236 .

29. Hill DS (1987) Agricultural insect pests of temperate regions and their control Cambridge University Press, USA.

30. Belluco S, Losasso C, Maggioletti M, Alonzi CC, Paoletti MG, et al. (2013) Edible insects in a food safety and nutritional perspective: A critical review. Comprehensive Reviews in Food Science and Food Safety 12: 296-313.

31. Depledge MH, Rainbow PS (1990) Models of regulation and accumulation of trace metals in marine invertebrates. Comparative Biochemistry and Physiology Part C: Comparative Pharmacology 97: 1-7.

32. Diez-Ortiz M, Lahive E, Kille P, Powell K, Morgan AJ, et al. (2015) Uptake routes and toxicokinetics of silver nanoparticles and silver ions in the earthworm Lumbricus rubellus. Environmental toxicology and chemistry 34: 2263-2270.

33. Laverack MS (1961) Tactile and chemical perception in earthworms-II responses to acid $\mathrm{pH}$ solutions. Comparative Biochemistry and Physiology 2 : 22-34.

34. Geissen V, Brummer GW (1999) Decomposition rates and feeding activities of soil fauna in deciduous forest soils in relation to soil chemical parameters following liming and fertilization. Biology and Fertility of Soils 29: 335-342.

35. Tourinho PS, van Gestel CA, Lofts S, Soares AM, Loureiro S (2013) Influence of soil $\mathrm{pH}$ on the toxicity of zinc oxide nanoparticles to the terrestrial isopod Porcellionides pruinosus. Environ Toxicol Chem 32: 2808-2815. 